\title{
Methods of instrument testing of smoke detectors performance
}

\author{
Sergey Dubov ${ }^{1, *}$, Igor Babikov ${ }^{1}$, Mihail Vasilyev ${ }^{1}$, and Leonid Tanklevsky ${ }^{1}$ \\ ${ }^{1}$ Peter the Great St.Petersburg Polytechnic University, 195251, St.Petersburg, Polytehnicheskaya st., \\ 29
}

\begin{abstract}
This article is devoted to the currently relevant task - determining the real operability of the smoke detector and developing a method for the rapid diagnosis of fire detectors included in the fire alarm loop. In the process, the sensitivity of the smoke optoelectronic fire detector was checked.
\end{abstract}

\section{Introduction}

The analysis of statistics shows that in the event of a real fire, the systems of fire automatics do not work or work inadequately and do not fulfill their function. [26] This is due to the fact that, often, when designing, installing or during maintenance, errors and violations are made that cause system's malfunction. One of the main problems is that during visual inspection, focusing on the control panel and evaluating the correctness of the placement of fire detectors, it is impossible to assess the real operation of the fire alarm system. According to the established practice, fire alarm elements are selectively checked under laboratory conditions on expensive stationary equipment and in fact only when the product is put into production or every few years during the manufacture of the product by the manufacturer. The quality of products sold is not actually controlled. Identifying the causes of inadequate fire alarm operation and their elimination will increase the effective-ness of fire protection. The result of improving the efficiency of fire automatics is to ensure its timely malfunction detection and reduce possible damage. [17,33]

Successful operation requires not only the technical ability of the fire detector to detect smoke, the stability of its electrical characteristics, but also the ability of the system perceive the incoming electrical signal adequately. At present, there are no requirements in national standards for the stability and unification of the electrical parameters of fire detectors in the standby mode and when it is triggered. At the same time, there is no rigid rationing to the electrical characteristics of the fire alarm loop. Ways of signal processing by the control panel are not fully protected from the formation of false signals, which does not guarantee an adequate response to the operation of the fire detector.

The performance of each element of fire automatics affects the operation of the entire system. Thus, to achieve the basic requirement for a fire alarm system - the identification of fire hazard factors is possible only with the coordinated work of the entire system. This

\footnotetext{
*Corresponding author: sergeidubov95@mail.ru
} 
interaction is not always provided in practice. In connection with the active development of business in our country, more than 150 types of smoke detectors and several dozens of receiving and control devices are in mass-production. Their joint work should ensure timely detection of the fire. However, due to the fact that detectors are produced by some companies and the receiving and control devices by other companies, it is quite problematic to combine their electrical characteristics. Moreover, a number of products do not meet the technical parameters described in the technical passport, not to mention the national standards. Adjustor is responsible for combining various characteristics in order to put the fire protection system into operation, but sometimes fails to complete the task competently and responsibly. The customer has practically no means of instrumental assessment of the quality and effectiveness of the installed fire alarm system. [2]

For normal operation of the detector, it is extremely important to control the sensitivity of the detector and its compliance with the technical passport data. Measuring the sensitivity of smoke detectors at the facility requires expensive equipment that is almost unavailable in Russia. Some manufacturers of detectors, even at the production stage, deliberately change the sensitivity, decreasing it up to 2 times to eliminate false alarms, thereby "compensating" for the negative effect of the defect [10].

Current situation allowed us to formulate the following research topic. Namely, to develop approaches to verify the operability of smoke detectors in the fire alarm loop, for this, at the initial stage, it was necessary to carry out a standard check of the sensitivity of smoke detectors. We have developed a stand for this purpose (Figure 1).

\section{Methods}

The first stage was a standard test of the sensitivity of smoke threshold detectors in accordance with the requirements of GOST R 53325-2012 "Technical means of fire automatics. General requirements and test methods "[10]. For this purpose, the detector connected to the laboratory power supply unit with a maximum consumption current limiter was placed in the "smoke channel stand" installation in accordance with Appendix D of GOST 53325-2012.

The stand consisted of: 1 - fan forcing and mixing smoke; 2 - hinged cover for installation of the test sensor with a glass viewing window; 3-platform with a rotating device on which the detector is installed; 4-tested optoelectronic point smoke fire detector(OPSFD); 5temperature sensors and air flow rate; 6-direction of air flow; 7 linearizer; 8 - device for measuring the specific optical density; 9-heater; 10- air flow rate regulator; 11- hole for removing soot and cleaning. 


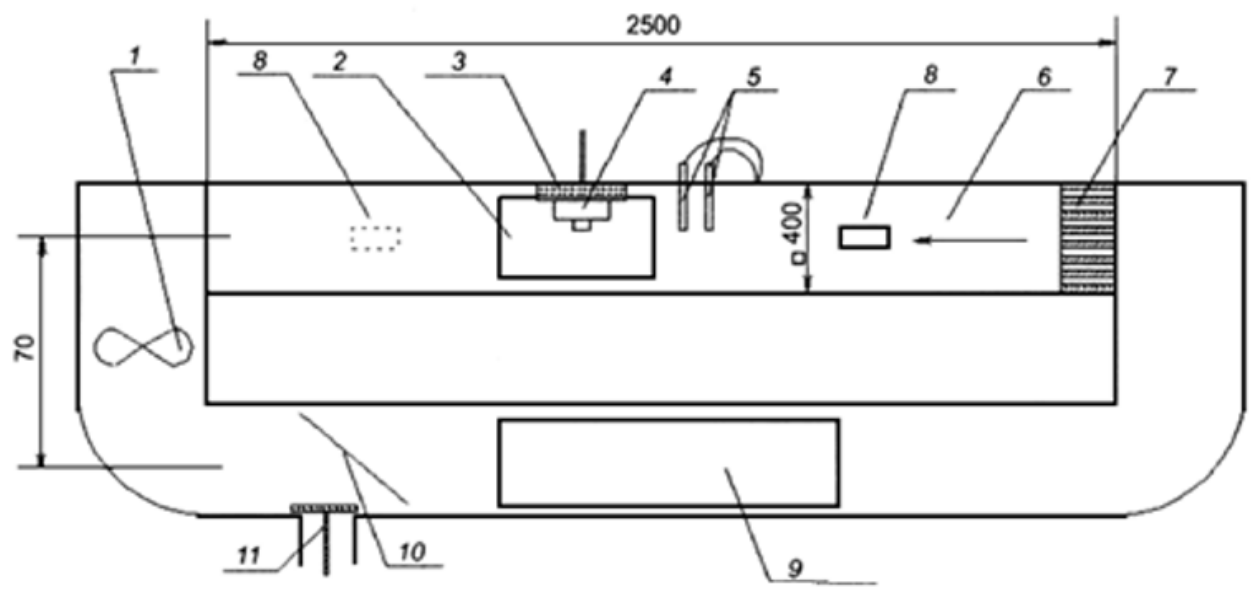

Fig. 1. Smoke channel stand

Then, in the air flow of a given value in the range from $0.2 \mathrm{~m} / \mathrm{s}$ to $0.8 \mathrm{~m} / \mathrm{s}$, the smoke source (cotton wick) was set on fire in the smoldering mode and as the chamber filled with smoke the change in the optical density of the smoke was monitored by an optical laser meter of smoke density. The experiment was carried out until the moment when the fire detector was triggered or the change in optical density exceeded $2 \mathrm{~dB} / \mathrm{m}$. Further, the same detector, after purging with fresh air and cleaning the chamber from smoke, was again placed in the chamber and the experiment was repeated at a different air flow rate. Thus, each test detector was tested 3 times. The results of inspections are reflected in the table №1.

\section{Results}

In the course of the work, we selected several types of detectors: FD 212-5M f. No. 1998, FD 212-5P f. No. 1999, FD 212-3CM f. No. 349717, FD 212-3SU f. No. 1972140, FD 2123SU f. No. 6884, FD 212 44CB f. No. 1725, and FD 212-44CB-D f. No. 2407, APPOLO No. 0299-01476, APPOLO No. 0299-01477.

Nevertheless, it was found that FD 212-3CM modification gave stable performance in all test modes. This allowed later, based on the design of this detector, to create a device that generates a signal in analog form. Repeated additional tests showed a clear correlation of this signal with the optical density of smoke, measured by a laser optical smoke meter in the range up to $2 \mathrm{~dB} / \mathrm{m}$ to the requirements of GOST 53325 [10].

Table 1. Sensitivity of threshold opto-electronic smoke detectors

\begin{tabular}{|c|c|c|c|c|c|c|c|c|c|c|c|c|c|}
\hline № & $\begin{array}{c}\text { No. } \\
\text { number } \\
\text { and type } \\
\text { of } \\
\text { detector }\end{array}$ & $\begin{array}{c}\text { air } \\
\text { speed } \\
\mathrm{m} / \mathrm{s}\end{array}$ & U0 & U1 & $\mathrm{Db} \backslash \mathrm{M}$ & $\begin{array}{c}\text { air } \\
\text { speed } \\
\mathrm{m} / \mathrm{s}\end{array}$ & U0 & U1 & $\mathrm{Db} \backslash \mathrm{M}$ & $\begin{array}{c}\text { air } \\
\text { speed } \\
\mathrm{m} / \mathrm{s}\end{array}$ & U0 & U1 & $\mathrm{Db} \backslash \mathrm{M}$ \\
\hline 1 & $\begin{array}{c}\text { FD 212- } \\
\text { 5M f. № } \\
1998\end{array}$ & 0,2 & 3,54 & 3,42 & 0,30 & 0,4 & 3,53 & 3,47 & 0,15 & 0,8 & 3,52 & 3,44 & 0,20 \\
\hline 2 & $\begin{array}{c}\text { FD 212- } \\
\text { 5P f. № } \\
1999\end{array}$ & 0,2 & 3,5 & 3,37 & 0,33 & 0,4 & 3,51 & 3,45 & 0,15 & 0,8 & 3,49 & 3,43 & 0,15 \\
\hline
\end{tabular}




\begin{tabular}{|c|c|c|c|c|c|c|c|c|c|c|c|c|c|}
\hline 3 & $\begin{array}{c}\text { FD 212- } \\
\text { 3CM f. } \\
\text { № } \\
\text { 349717 }\end{array}$ & 0,2 & 3,5 & 3,46 & 0,10 & 0,4 & 3,61 & 3,57 & 0,10 & 0,8 & 3,49 & 3,45 & 0,10 \\
\hline 4 & $\begin{array}{c}\text { FD 212- } \\
\text { 3CУ f. № } \\
1972140\end{array}$ & 0,2 & 3,52 & 3,46 & 0,15 & 0,4 & 3,64 & 3,58 & 0,14 & 0,8 & 3,47 & 3,41 & 0,15 \\
\hline 4 & $\begin{array}{c}\text { FD 212- } \\
\text { 3SU f. № } \\
\text { 6884 }\end{array}$ & 0,2 & 3,47 & 3,38 & 0,23 & 0,4 & 3,66 & 3,61 & 0,12 & 0,8 & 3,58 & 3,53 & 0,12 \\
\hline 5 & $\begin{array}{c}\text { FD 212 } \\
\text { 44CB f. } \\
\text { № 1725 }\end{array}$ & 0,2 & 3,43 & 3,41 & 0,05 & 0,4 & 3,67 & 3,65 & 0,05 & 0,8 & 3,48 & 3,44 & 0,10 \\
\hline $\begin{array}{c}\text { FD 212- } \\
\text { 44CB-D } \\
\text { f. № } \\
2407\end{array}$ & 0,2 & 3,44 & 3,4 & 0,10 & 0,4 & 3,67 & 3,64 & 0,07 & 0,8 & 3,44 & 3,42 & 0,05 \\
\hline 7 & $\begin{array}{c}\text { APPOLO } \\
\text { №0299- } \\
\text { 01476 }\end{array}$ & 0,2 & 3,98 & 3,93 & 0,11 & 0,4 & 3,96 & 3,92 & 0,09 & 0,8 & 3,95 & 3,89 & 0,13 \\
\hline 8 & $\begin{array}{c}\text { APPOLO } \\
\text { №0299- } \\
\text { 01477 }\end{array}$ & 0,2 & 3,96 & 3,88 & 0,18 & 0,4 & 3,97 & 3,91 & 0,13 & 0,8 & 3,95 & 3,89 & 0,13 \\
\hline
\end{tabular}

The tests (table 1) showed that a number of detectors do not correspond to the parameters specified by manufacturers. This is due to the fact that the sensors were either poorly adjusted at the factory or structurally flawed and, therefore, their sensitivity did not correspond to GOST 53325 at various air flow rates.

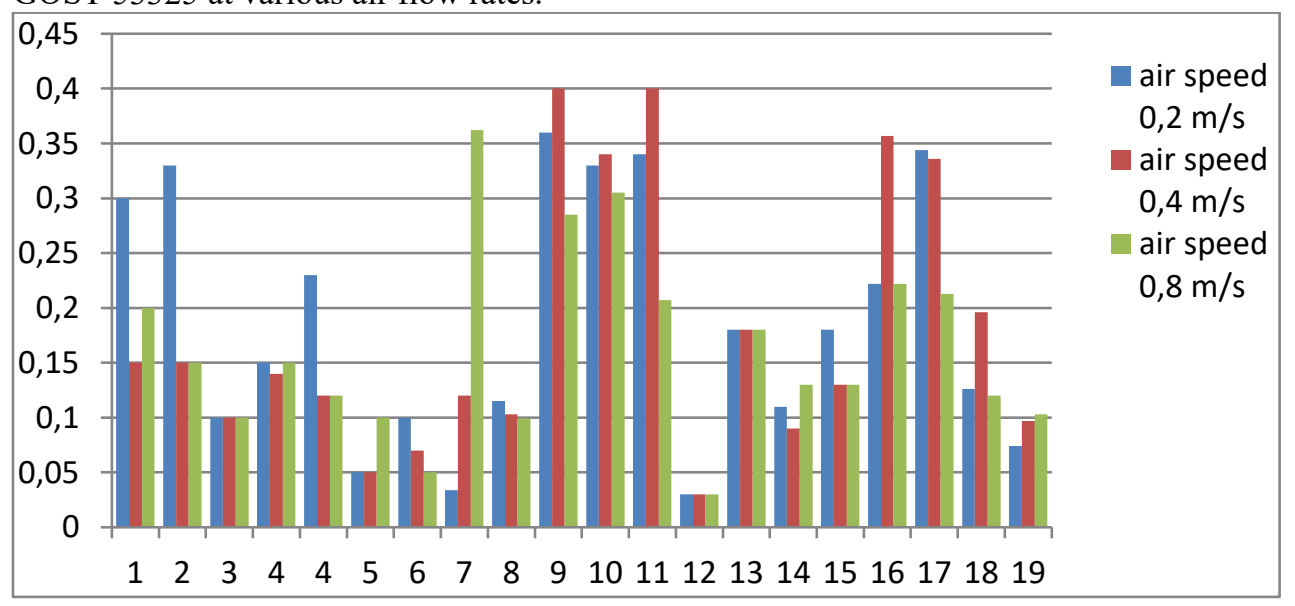

Fig. 2. The sensitivity of threshold smoke detectors at different air flow rates.

\section{Conclusions}

The tests have shown that a number of detectors do not correspond to the parameters specified by manufacturers. This is due to the fact that the sensors were either poorly adjusted at the factory, or structurally flawed, due to that their sensitivity did not correspond to GOST 53325 
at various air flow rates. Nevertheless, it was found that the modification FD 212-3CM gave stable performance in all test modes. This allowed later, based on the design of this detector, to create a device that generates a signal in analog form. Repeated additional tests showed a clear correlation of this signal with the optical density of smoke, measured by laser optical smoke meter in the range up to $2 \mathrm{~dB} / \mathrm{m}$ to the requirements of GOST 53325 [10].

Repeated testing confirmed good repeatability of the results, which allows, after testing in an accredited center of the FD 212-3CM modification device, to assign it the status of a signal quality optoelectronic point smoke fire detector (SQOPSFD).

This device is autonomous, compact. There is a possibility of prompt installation of the SQOPSFD in close proximity to the detector being checked.

When conducting fire tests at the facilities of the SQOPSFD, it can be used to assess the smoke sensitivity of fire detectors included in the fire alarm loop.

As a result of the work carried out, we identified the necessity of rationing and checking during certification tests, as well as at the input control, not only of the average current consumption of the detector in standby mode, but also in pulsed mode.

A method is proposed for stabilizing the work of an alarm loop, including a two-threshold one, by normalizing the perception of the signal "Fire" from the activated detector by replacing Rtob with an ES (5.5mA) created at Gefest LLC.

\section{References}

1. V. Bakanov, Safety Algorithm magazine 6, 9 (2010)

2. M.A. Vasilyev, Development of methods for functional control of fire alarm equipment and their technical implementation. Abstract of a PhD thesis, (St. Petersburg, 1999)

3. Departmental construction standards 25-09.67-85 Rules of production and acceptance of work. Automatic installation (Standardinform, Moscow, 1985)

4. GOST 12.1.004-91 Occupational safety standards system. Fire safety (Publishing house of standards IPK, Moscow, 1996)

5. GOST R 1.4 - 2004 Standardization in the Russian Federation. Standards of organizations. General provisions (Standardinform, Moscow, 2007)

6. GOST 1.5 - 2001 Interstate Standardization System (MGSS). Interstate standards, rules and recommendations for the construction, presentation, design, content and designation (with Amendment N 1) (Standardinform, Moscow, 2010)

7. GOST 1.5-2012 Standardization in the Russian Federation. Standards national. Rules of construction, presentation, design, and notation. (Amended, with a change in N 1) (Standardtiform, Moscow, 2013)

8. GOST 12.1.004-91 Occupational safety standards system. Fire safety (Publishing house of standards IPK, Moscow, 1996)

9. GOST 2.102-2013 Unified system for design documentation (USDD). Types and completeness of design documents (Standardtiform, Moscow, 2014)

10. GOST 53325 - 2012 Fire equipment. Technical means of fire automatics. General technical requirements and test methods (Standardtiform, Moscow, 2012)

11. GOST R IEC 60068-2-1-2009 Testing for exposure to external factors. Part 2-1. Tests (Standardtiform, Moscow, 1990)

12. D.S. Zemlyansky, K.V. Zorina, SPbPU Science Week: Proceedings of a scientific conference with international participation. Graduate School of Techno-sphere Security XLVI 123 (2017)

13. I.G. Neplohov, Safety Algorithm magazine 5, 7 (2010) 
14. I.G. Neplohov Problems of connecting heat detectors with indicators, Catalogue "Fire Safety - 2011" (Grotek, Moscow, 2011)

15. I.G. Neplohov, Journal "Security Algorithm" 3, 5 (2008)

16. I.G. Neplohov, Security Systems Magazine 5, 6 (2007)

17. On Amendments to Certain Legislative Acts of the Russian Federation on the Issues of Ensuring Fire Safety, Training the Population in the Field of Civil Defense and Protection in Emergencies: Fedr. Law of December 30, 2015 No. 448, adopted by the State. Duma December 25, 2015 (FGI VNIIPO, Moscow, 2015)

18. E. Gumerova, O. Gamayunova, L. Shilova, MATEC Web of Conferences 106, 06020 (2017)

19. A. Gorshkov, V. Murgul, Advances in Intelligent Systems and Computing 692, 577-591 (2018)

20. A. Ustinov, O. Zybina, L. Tanklevsky, V. Lebedev, A. Andreev, E3S Web of Conferences 33, 02039 (2018)

21. On Amendments to the Code of Administrative Offenses of the Russian Federation on fire safety issues. Feder. Law of June 3, 2011 No. 120, adopted by the State. Duma May 10, 2011, approved by The Federation Council May 25, 2011 (FSI VNIIPO, Moscow, 2011)

22. On the licensing of certain types of activities. Feder. Law of December 30, 2015 No. 99, adopted by the State. Duma 22 April 2011, approved by The Federation Council April 27, 2011 (FSI VNIIPO, Moscow, 2015)

23. S.V. Efremov, O.V. Romantsova, V.B. Ulybin, Acta Astronautica (Article in Press)

24. Set of Rules 5.13130.2009 Fire protection systems. Installation of fire extinguishing automatic. Norms and rules of design (Standartinform, Moscow, 2009)

25. V. Burlov, O. Lepeshkin, Transportation Research Procedia 20, 94-99 (2017)

26. Y. Vetyukov, E. Oborin, M. Krommer, V. Eliseev, Mathematical and Computer Modelling of Dynamical Systems 23 (1), 40-54 (2017)

27. Fire statistics for 2016 and 2017. [Electronic resource] - Access Mode: http://www.mehs.gov.ru/

28. E.S. Burlakov, G.A. Evdokunin, A.S. Karpov, Proceedings of the 2017 IEEE Russia Section Young Researchers in Electrical and Electronic Engineering Conference ElConRus 2017 260-264, 7910543 (2017)

29. Technical Regulations on Fire Safety Requirements. Feder. Law of July 22, 2008 No 123, adopted by the State Duma July 04, 2008, approved by The Federation Council July 11, 2008 (FSI VNIIPO, Moscow, 2008)

30. The sensitivity of the smoke detector and its control [Electronic resource]. - Access mode https://algoritm.org/

31. Efficiency of fire protection: threshold and analogue addressable detectors [Electronic resource]. - Access mode http://agro-st.ru/

32. O. Zybina, M. Gravit, Y. Stein, IOP Conference Series: Earth and Environmental Science 90 (1), 012227 (2017)

33. Set of Rules 2.13130.2012 Fire protection systems. Ensuring the fire resistance of objects under protection (Standardinform, Moscow, 2012)

34. A. Tumanov, V. Gumenyuk, V. Tumanov, IOP Conference Series: Earth and Environmental Science 90 (1), 012027 (2017)

35. A. Pinaev, M. Nikolsky, Safety Algorithm magazine 6, 8 (2007) 
36. G.I. Korshunov, S.L. Polyakov, L. Shunmin, IOP Conference Series: Earth and Environmental Science 87 (6), 062009 (2017)

37. S.V. Bobylev, I.A. Ovid'ko, Acta Materialia 124, 333-342 (2017)

38. V.V. Sharmanov, T.L. Simankina, A.E. Mamaev, Magazine of Civil Engineering 69(1), 77-88 (2017)

39. V. Artiukh, V. Mazur, A. Adamtsevich, MATEC Web of Conferences 106, 04001 (2017)

40. N.V. Smirnov, S.G. Tsarichenko, V.L. Zdor, B.P. Starshinov, M.V. Savin Regulatory and technical documentation on the design, installation and operation of fire extinguishing systems, fire alarms and smoke removal systems. Teaching manual (VNIIPO, Moscow, 2004)

41. L. Tanklevskiy, A. Tsoy, A. Snegirev, Fire Safety Journal 91, 614-623 (2017) 